\title{
The ethical and epistemological pitfalls of translating phylogenetic HIV testing: from patient-centered care to surveillance
}

\author{
Tony Sandset ${ }^{1 凶}$
}

In both HIV science and public health policy, efforts to end the HIV epidemic are increasingly focusing on molecular HIV surveillance as a helpful tool for identifying, intervening in and controlling the disease. HIV surveillance is meant to identify clusters of genetically similar viral strains in near real-time in communities and areas where transmissions occur, and then to intervene by means of enhanced public health approaches. This article critically engages with how molecular HIV surveillance-a practice and technology portrayed as a benign public health intervention-empties and purifies many of the social and political contexts of HIV transmissions. McClelland et al. (Crit Public Health 1-7, 2019) see the rise of molecular HIV surveillance as a form of "repurposing" of clinical phylogenetic testing done in the context of HIV care. In this article, I argue that this so-called repurposing can be understood as a form of "translation". Looking at how phylogenetic HIV testing has been translated from clinical, patient-centered use to a form of molecular HIV surveillance, I seek to map some of the potential ethical and epistemological pitfalls of such a translational process. More specifically, I look at the unintended consequences of translating a particular evidence-based practicephylogenetic HIV testing-from one usage to another. To this end, I engage with Michel Foucault and his work on the biopower of medicine, exploring how such power disciplines subjects into undergoing a form of medical surveillance that influences norms and behaviors. Ultimately, I argue that the translation of phylogenetic testing from patient-centered care in the clinic to a form of epidemiological surveillance needs to be critically examined in order to avoid ethical and potentially detrimental consequences for HIV-affected communities.

\footnotetext{
${ }^{1}$ University of Oslo, Oslo, Norway. ${ }^{凶}$ email: t.j.sandset@medisin.uio.no
} 


\section{Introduction}

fforts to end the HIV epidemic are increasingly focusing on molecular HIV surveillance as an identification and intervention tool (Control, 2018; Oster et al., 2018a, 2018b). The tool aids in identifying clusters of genetically similar viral strains in near real-time in communities and areas where transmissions occur, and then intervenes by means of enhanced public health approaches, such as linking people to systems of care, treatment, testing, and further diagnosis (Little et al., 2014; Poon et al., 2016).

As such, the US Centers for Disease Control (CDC) has heralded molecular surveillance as a "critical step toward bringing the nation closer to the goal of no new infections."1 Molecular HIV surveillance is also practiced in Canada (Poon et al., 2016), and studies on its usage have been conducted in Spain (GonzálezAlba et al., 2011), Italy (Lai et al., 2020), and France (Chaillon et al., 2017; Wirden et al., 2019). Every American health authority deploying this approach "takes aggregate data from people's HIV blood tests and compares it molecularly to identify groupings of genetically similar virus that are connected temporally, geographically, and by stage of infection. This enables surveillance to take place among populations [...] and in locations where HIV is being transmitted among people not well-connected to care" (McClelland et al., 2019). The CDC argues that molecular surveillance is better equipped to discover and intervene in so-called "risk networks," as it can help overcome traditional barriers to disease surveillance. ${ }^{2}$ For example, molecular surveillance can purportedly eliminate the current delays between HIV infection and diagnosis-time lags that can worsen health outcomes and increase the risk of onwards HIV transmission. The approach also takes population mobility into account and helps track and trace the sexual and drug-taking partners of newly infected HIV patients (Oster et al., 2018a; Oster et al., 2018b).

This article critically engages with how molecular HIV surveillance-a practice and technology portrayed as a benign public health intervention-empties and purifies many of the social and political contexts of HIV transmission (McClelland et al., 2019, p. 2). McClelland et al. see the rise of molecular HIV surveillance as a "repurposing" of clinical phylogenetic testing done in the context of HIV care. I argue that, because this so-called repurposing is used in certain science and technology studies (STS), it can be understood as a form of "translation" (Brown, 2002; Callon, 1984). Looking at how phylogenetic HIV testing has been translated from clinical, patient-centered use to a form of molecular HIV surveillance, I seek to map some of the potential ethical and epistemological pitfalls of such a translational process. More specifically, I look at the unintended consequences of translating a particular evidence-based practice-phylogenetic HIV testingfrom one usage to another. To this end, I engage with Michel Foucault and his work on the biopower of medicine, exploring how such power disciplines subjects into undergoing a form of medical surveillance that influences norms and behaviors (Foucault, 2002, 2008, 2012; Foucault et al., 2010).

\section{Defining molecular HIV surveillance: from clinical usage to epidemiological surveillance}

Phylogenetic testing is done to map the genetic material of various HIV strains and thus create an evolutionary or genealogical tree of their relationship. Castro-Nallar et al. observed that the "first applications of phylogenetics to the study of HIV date from the early 1990s and were aimed at inferring the origins of HIV-1 and the classification of HIV into different types (1 and 2), groups ( $\mathrm{M}, \mathrm{N}, \mathrm{O}$ within HIV-1), and subtypes (A-D, F-H, and $\mathrm{J}$ and $\mathrm{K}$ within Group M of HIV-1)" (Castor et al., 2012; Huet et al., 1990). Castor-Nallar et al. further state that "today, phylogenetic analysis has become a common practice of many HIV/AIDS research programs, due mainly to the many insights these analyses can provide and the novel questions they can address over a variety of topics related to HIV biology" (Castro-Nallar et al., 2012, p. 3). As a clinical tool in patient-centered care, such testing is mainly aimed at mapping resistance to HIV antiretroviral (ARV) drugs. Against this backdrop, the use of such tests can be seen as "bridging the gap" between laboratory science and its clinical application-or, more generally, as putting research-based knowledge into practice.

In many wealthy countries, a person enrolled in HIV care is given a range of blood tests, including a genotyping of their HIV strain. Using genetic sequencing, the test produces three key pieces of data: "(1) the viral subtype, (2) the presence of drugresistant variations, and (3) phylogenetic analysis to examine how viral sequences are related" (McClelland et al., 2019, p. 2). The latter result is not collected as part of patient care and thus extends the original clinical usage of genotyping as a means of repurposing phylogenetic testing to the realm of epidemiological surveillance.

In the practical realm of HIV surveillance, surveillance authorities register these results in databanks. In the USA these authorities include the National HIV Surveillance System, and in Canada the BC Center for Excellence in HIV/AIDS (McClelland et al., 2019, p. 2). However, although phylogenetic testing cannot conclusively determine the directionality of transmission, it can establish a certain degree of genetic kinship between viral strains. This functions to produce clusters of genetically similar HIV strains that can then be monitored as they occur and registered in the relevant databases. The CDC is particularly interested in molecular clusters with upwards of five new HIV transmissions within the past 12 months and no more than $0.5 \%$ genetic difference between them (CDC, 2018). The CDC further notes that, once detected, these transmission clusters require that various efforts be made to identify and intervene in both the molecular HIV cluster and the extended risk networks (CDC, 2018). Risk networks are defined as "persons among whom HIV transmission has occurred and could be ongoing. This network includes persons who are not HIV-infected but may be at risk for infection, as well as the HIV-infected persons in the transmission cluster."3 Such identification and intervention is thus critical and can be achieved through HIV testing offers, as well as linkage to care and other preventive tools such as PrEP (pre-exposure prophylaxis).

I argue that one must understand this repurposing of phylogenetic testing from clinical care to HIV surveillance as going beyond the traditional path of translating medical knowledge from bench to trench. In the classical sense, medical knowledge translation means taking laboratory science and turning it into clinical interventions, a process ostensibly driven by evidencebased practice.

However, less attention has been focused on what happens when a medical technology first used to test HIV drug resistance is repurposed. What happens when the same technology crosses from one healthcare regime (clinical usage) to another (public health surveillance)? To answer this question, I turn to the sociology of translation and STS perspectives as vehicles for critiquing the repurposing of phylogenetic testing into an epidemiological surveillance tool.

\section{Repurposing as translation}

Phylogenetic HIV testing and its repurposing as a molecular HIV surveillance tool can be read as a form of translation. An article in The Lancet HIV, for instance, highlights the need to "translate phylogeny into action for HIV surveillance" (Gardy, 2016). 
Addressing the gap between laboratory science and applied public health, the author relates how phylogenetic HIV testing as a tool for molecular HIV surveillance "bridges the laboratory with frontline public health" and that "pathogen sequencing is beginning to move out of the reference laboratory and into the field" (Gardy, 2016, p. e197). I argue, however, that this translation of molecular HIV surveillance illustrates how such technology has gone from bench to bedside to surveillance. My addition of this extra step to the translational chain is a call for a stronger focus on the new effects, associations, and pitfalls that emerge from this bridging process.

To set the stage, I would like to cite historian of science Michael Wintroub. He states: "translation is a common word. However, its meaning cannot be reduced to common usage: to turn one language into another. Made from the combination of two other words, trans, meaning to crossover or go beyond, and fero (whose supine form is latum), meaning to bear or carry, translation signifies movement and transference, transport, and carrying over" (Wintroub, 2015a, p. 98). In another article, Wintroub notes that "translation is not just a word with a history; it is a historical process-a colonial practice having to do with the extension of knowledge and power across space and time" (Wintroub, 2015b, p. 1185). I therefore argue that the repurposing of phylogenetic testing is a form of translation wherein phylogenetic testing moves out of the clinic and into the domain of epidemiological surveillance. It implies a crossover from clinical care to public health and thus extends the knowledge extracted from phylogenetic HIV testing into public health surveillance. This extension is important, for in the translational process this knowledge ceases to cover HIV drug resistance alone and suddenly concerns transmissions chains and risk networks as well.

Therefore, as I see it, the act of repurposing phylogenetic HIV testing entails change, transformation, and the creation of new connections and associations. These connections often differ from those previously linked to the clinical, patient-centered application of the testing - a situation that leaves this new usage open to myriad potential pitfalls. Here, I take inspiration from John Law and his insights that "to translate is to transform, and in the act of transforming a breaking of fidelity towards the source is necessarily involved. Indeed, translation ("traduction") is also a kind of betrayal, a treason ("trahison") (Law, 2006). Indeed, repurposing phylogenetic testing for HIV surveillance involves radically transforming the clinical usage of this test and thus making the knowledge extracted from the same data - blood samples - serve one set of purposes in the clinic and another entirely in the name of public health surveillance.

\section{Methods}

This article is based on an analysis of academic journal articles related to HIV transmission clusters and the use of molecular HIV surveillance, as well as on guidelines regarding the use and implementation of molecular HIV surveillance.

As the scholarship on phylogenetic testing and its usage as a public health surveillance tool is immense, I sought to restrict the initial literary search to a few decisive parameters. I therefore focused on how molecular HIV surveillance is implemented and executed in the USA, Canada, and Europe and on how such surveillance has often been repurposed to target key populations such as men who have sex with men (MSM), transgender women, and immigrants. Since my interest was in how HIV science frames the usefulness of such technologies in epidemiological surveillance, I further confined my search to articles either regarding studies where an intervention had been carried out or examining the possible practical implementation of such technologies. Commentaries and position papers were therefore excluded, as were articles that dealt only with phylogenetic testing as a data extraction method for mapping HIV genotypes, drug resistance, and the etiology of HIV strains.

To search titles in the Google Scholar search engine, I entered the keywords "HIV + molecular surveillance." This search yielded 46 results. Of these 46, 11 concerned the USA, Canada, or European countries. Next, I read the abstracts of the 11 articles to ensure that they corresponded with the scope of my own article, which aimed to examine molecular HIV surveillance as a tool for public health interventions. Consequently, I included articles specifically focused on mapping transmission or risk clusters, but excluded studies aimed at mapping and characterizing such aspects as drug resistance and the genotype dominating the local ecology of HIV, as well as those concerning viral load. In this way, I determined that eight articles both fit the search criteria and focused on the above-outlined themes.

I then conducted another search, this time with the keywords "HIV + phylogenetic analysis," which yielded 212 results. Employing the same selection process as above, I found seven articles that matched the search criteria. For my final Google Scholar search, I entered the keywords "HIV + transmission cluster." This produced 66 articles, four of which matched the final search criteria.

I repeated this entire search process in the PubMed database. The first search yielded 16 articles, but they all overlapped with those found in the Google Scholar search. The second search, containing the keywords "HIV + phylogenetic analysis" produced a total of 136 articles. Applying the criteria of geographical location and abstract content, I reduced the number of articles to 10, but after a check for doubles only two remained. Finally, the third search, containing the keywords "HIV + transmission clusters," yielded only three articles, all of which either were duplicates or failed to meet the search criteria.

The search process provided an initial pool of 463 articles matching the keywords of titles, after which the abstracts were read for relevance. The ultimate pool fitting all the search criteria contained 22 articles.

\section{Content analysis and "what is the problem represented to be?"}

I analyzed the articles by employing a close reading strategy informed by a focus on thematic content analysis (Elo and Kyngäs, 2008; Mayring, 2004) along with Carol Bacchi's methodological framework of "what is the problem represented to be?”(WPR) (Bacchi, 2012, 2015; Bacchi and Goodwin, 2016). Crucially, I used Bacchi's WPR to draw out the meaning-making content of the documents to be analyzed and thus to uncover a set of "problems" or problematizations hidden in the text. Bacchi proposes six questions of use in such an analysis: (i) What is the problem represented to be in the specific policy or text? (ii) What are the deep-seated assumptions underlying this representation of the problem? (iii) How has this representation of the problem come to be a problem? (iv) What is left unproblematic in the policy/text, and where are the "silences"? (v) What effects are produced by this representation of the problem? And finally, (vi) how has this representation of the problem been disseminated, defended, and produced? (Bacchi and Goodwin, 2016, p. 20). As applying all six questions is beyond the scope of this article, a content analysis was generated only on the basis of questions (i), (ii), and (v).

Through this process, two main themes emerged: a focus on the role of immigration in local HIV dynamics and a clear emphasis on uncovering hidden risk groups. Two more topics emerged through the discursive silences noted, i.e., what the 
articles did not say. The first was coded as "molecular truthtelling", which served to highlight the articles' various assumptions about how to extract molecular data and thus "know" the truth about the subject, their HIV risk, and their placement in transmission clusters and risk networks. The second arose from the articles' surprising silence regarding ethical issues of consent, stigma, and criminalization.

The methodology and material have several limitations. First, the geographical focus on the USA, Canada, and Europe meant that several important geographical locations using or considering using molecular HIV surveillance had to be excluded, among them several African nations, as well as some in South America and Asia. The narrow set of search criteria also led many overlapping articles to be omitted. Methodologically speaking, qualitative content analysis has received criticism for focusing too strongly on the overt meanings of a text at the cost of its latent and hidden meanings (Mayring, 2004). This article seeks to mitigate some of these shortcomings by including Bacchi's WPR in a way that problematizes what is not said in the material analyzed. Finally, since only one author conducted the analysis, some selection bias may be present.

\section{Inferring the role of immigration in HIV dynamics: the figure of the immigrant}

The idea that immigration and immigrants influence local HIV epidemic dynamics is a well-known issue in the social history of the HIV epidemic. For example, in the seminal book AIDS and Accusation (Farmer, 2006), Paul Farmer traces a "geography of blame" to Haitians, who were labeled as the ones to "introduce" HIV in the USA, connecting this blame to underlying notions of eurocentrism and a colonial legacy of racism. Steven Epstein (Epstein, 1996), Paula Treichler (Treichler, 1999), and Thurka Sangramoorthy (Sangaramoorthy, 2014) make similar arguments. Others have connected the notion of this influence to public health policies that test immigrants more frequently and to a form of securitization that frames HIV testing of immigrants as a means of keeping the national population safe from HIV (Ingram, 2008; Persson and Newman, 2008). Little wonder, then, that molecular HIV surveillance has deployed this problem as an argument for using molecular HIV surveillance to map the impact of immigration on local HIV dynamics.

Many of the articles analyzed explicitly problematize the role of immigration in local HIV dynamics (Dennis et al., 2015; González-Alba et al., 2011; 2013; Lai et al., 2020), often refracting the general problematization of immigration through the rationale that molecular HIV surveillance is a useful public health tool in as much as it "estimate[s] the impact of immigration on national and local HIV dynamics" (González-Alba et al., 2011), or how certain so-called risk groups with immigrant backgrounds contribute to "the import of other HIV strains" (Lai et al., 2020). The articles often position molecular HIV surveillance as a solution to the "problem" of immigration and HIV, often framing this position through a recourse to "targeted HIV preventive measures" (Dennis et al., 2015; González-Alba et al., 2011), such as linkage to care and HIV testing within risk networks.

Equally evident, however, is how immigrants are positioned as the active parts of onward HIV transmission. In one article focusing on the role of South American transgender women in HIV transmissions in Italy, the authors state that "our results indicate that South American transgenders largely contribute to the heterogeneity of HIV-1 in our country" (Lai et al., 2020). Moreover, the article concludes that South American transgender women often "do not practice safe sex" and that these women "could have a bridging role in the spread of HIV among both Italian MSM and heterosexuals" (Lai et al., 2020). Other articles from both Spain and the USA echo this emphasis on the active role of immigrant MSM and transgender women (Dennis et al., 2015; González-Alba et al., 2011), with a sub-theme being a focus on whether they acquired HIV in their countries of origin or destination. These articles relate their focus to the transmission dynamics occurring in these immigrants' destination countries and to the role immigrants play in onward HIV transmission there (Dennis et al., 2015; Lai et al., 2020), thus alluding to immigrants' active role in local HIV dynamics.

I argue that this focus expresses an asymmetric attribution of agency that emphasizes the role of the vector (immigrants in this case) rather than the pathogen (HIV) and the surrounding social network (socio-economic structures, culture, etc.) that facilitates onwards HIV transmission.

As with most calls to repurpose phylogenetic testing as a surveillance method, these articles stipulate that the detection of clusters is intended to offer a means of targeting specific groups with preventive programmed and of linking people into HIV treatment and care programmed. While I do not deny that such targeted intervention might have its place in HIV treatment and prevention programmed, I nevertheless contend that such efforts should be carefully communicated to affected communities, as well as to the broader public in a manner that avoids stigmatizing already vulnerable groups, such as immigrants. More generally, my point is that repurposing or translating phylogenetic testing as a tool for molecular HIV surveillance "black boxes" many of the aspects it purports to uncover. The cases cited above highlight the role of immigrant MSM and transgender women as being substantial, yet say little about the role of "native" Spaniards, Italians, or Americans in the transmission networks. The articles also overlook a broad range of socio-economic factors by focusing on the transmission dynamics of immigrants and their impact on local HIV dynamics.

In a case from Texas, Taylor and Sapién note that their results prompted news headlines in the local news ecology that read "Cluster of HIV Cases Involves Hispanic Men in San Antonio," concluding that such headlines might have made Hispanic and Latinx men more susceptible to stigma (Taylor and Sapién, 2020, p. 2). Accordingly, Taylor and Sapién argue that, while translating phylogenetic testing from clinical usage to molecular HIV surveillance might provide another a tool for targeted HIV prevention and care services, such translation might also intensify stigma in already stigmatized groups. This example also shows how molecular HIV testing can become entangled with the other highly stigmatizing discourses so rampant in the history of HIV.

Another case in point is US President Donald Trump's ostensible allusion to Haitian immigrants as "all having AIDS," which was widely circulated in the media. ${ }^{4}$ The media discourse of immigrants "bringing AIDS" to the USA, Canada, or Europe is a familiar trope. As such, although molecular surveillance can be a useful tool in HIV prevention and linkage to care, its framing and usage should be contextualized within a social and political climate where immigrants have been especially stigmatized as "carriers of HIV/AIDS." 5 Naina Khanna, executive director of Positive Women's Network, has recently raised concerns that in the USA phylogenetic data might be shared or demanded to be shared with Immigration and Customs Enforcement (ICE) or law enforcement, saying that "in this political environment, it would be foolish to assume such data would not be used to target immigrants or other vulnerable populations." ${ }^{6}$ Taylor and Sapién similarly state that some states require public health information to be shared with law enforcement (Taylor and Sapién, 2020, p. 3). Extreme care should be taken in how one frames immigrants when singling them out as "vectors" for HIV transmission and according them a form of "active" role in shaping "HIV landscapes.” Translating phylogenetic HIV testing from clinical 
care to a public health surveillance tool also runs an apparent risk of losing something in translation. In this case, a broad range of issues are lost if one looks solely at the transmission networks provided by molecular HIV surveillance. In other words, if one only traces the molecular bonds connecting people, one risks losing sight of the many complex and entangled factors that contribute to HIV transmission.

\section{Molecular truth-telling: uncovering hidden risk groups}

Men who have sex with men but do not disclose this have been a focal point of the HIV epidemic since its outbreak. In the field of biomedical epidemiology, bisexual men as vectors of onwards HIV transmissions into heterosexual communities has been in particular focus (Boulton et al., 1992; Chow et al., 2011; Montgomery et al., 2003; Wood et al., 1993), and anxiety in this regrard has further heightened concerns regarding potential onwards transmission to the female partners of non-disclosed men who have sex with men (ndMSM). As such, some studies examine how discourses about being "on the down-low" have rendered the figure of the African-American bisexual man as a pathological and dangerous object (Han, 2015; Stone, 2011). Since phylogenetic testing aims at uncovering "hidden populations" (German et al., 2017) where HIV is being transmitted, many of the articles analyzed highlight how phylogenetic testing can uncover and elucidate communities where HIV transmissions are ongoing, where an outbreak might be imminent, and where genetic clusters have formed, thus also inferring "hidden transmission networks" or routes. In alluding to such networks, the articles emphasize how some men acquired an HIV infection through sex with other men and not, as they had reported, through heterosexual contact.

Most of the articles focused on this issue stress that, until solved, the problem of MSM non-disclosure for various reasons constitutes a blind spot in HIV epidemiology (Hué et al., 2014; Ragonnet-Cronin et al., 2018). The articles also often highlight that non-disclosed MSM must be uncovered because they are a potential bridge between MSM HIV and heterosexual HIV dynamics (Ragonnet-Cronin et al., 2019). A final rationale for molecular HIV surveillance is that it could, for example, provide a means for notifying men who identify as heterosexual about their risk of acquiring HIV from having sex with transgender women (Ragonnet-Cronin et al., 2019). Non-disclosed MSM can be identified when one establishes genetic kinship between strains of HIV found in clusters of MSM and then compare this kinship to non-disclosed MSM. The various article authors infer kinship by genetically analyzing HIV subtypes found in clusters of people living with HIV and then linking these subtypes with those that dominate MSM communities. As such, these authors make an association and then trace a network through the genetic family resemblance of HIV-1 viruses linking MSM and non-disclosed MSM, in particular, black African men.

For example, black MSM are a focus of study in England, with the authors of one article stating that "taken together, our findings indicate that MSM unwilling to disclose their route of infection are more likely to be found amongst black African male heterosexuals than any other group. This is of importance since MSM of black or minority ethnic background is of the highest risk of acquiring HIV in the UK, and MSM perceived as heterosexuals may be missed by targeted prevention programmes" (Hué et al., 2014, p. 1973). In this optic phylogenetic testing offers a way of discerning what is hidden; that is, of how people have acquired HIV and thus what type of "risk exposure" heterosexual MSM have. "Male heterosexuals who have sex with men, but are not identified as "gay" are also likely to misreport their potential exposure" (Hué et al., 2014, p. 1973). The fact that phylogenetic testing can uncover the "truth" about a subject's sexuality without their having themselves reported it reinforces the notion that phylogenetic testing can go beyond tracing transmission networks and transmission chains.

The focus on men who identify as heterosexual but have sex with transgender women also serves to exemplify this notion. Here, too, the articles see phylogenetic molecular HIV surveillance as potentially useful in revealing the facts plus telling people something about their risks. In a review article scoping the uses of genetic HIV surveillance in "disclosed and cryptic HIV transmission risk," the authors pinpoint non-disclosed MSMs as one important such vector (Ragonnet-Cronin et al., 2019a). The article further argues that male partners of transgender women are key, as such partners represent groups at high risk of HIV (Ragonnet-Cronin et al., 2019a, p. 209). The article argues that these men are often unaware of belonging to a distinct risk group, for which reason they may underestimate their own HIV risk (Ragonnet-Cronin et al., 2019a, p. 209).

From this perspective, genetic HIV surveillance operates on the rationale of serving a dual purpose. First, it purportedly enables public health authorities to uncover a new risk group-heterosexual men who do not identify as gay but have sex with transgender women. Second, it reinforces these men's understanding of their true risk, as they may be unaware of belonging to a specific risk group.

However, the notion that phylogenetic tests can infer at the molecular level whether a man has had sex with another man without his having disclosed this information poses an ethical dilemma for those handling this data. Even researchers who argue for the usefulness and novelty of genetic HIV surveillance add this caveat. As Ragonnet-Cronin notes, "questioning heterosexual men regarding potential male partners risks alienating those men and leading to mistrust of health institutions" (Ragonnet-Cronin et al., 2019a, p. 209). Certainly, one might speculate that-if not handled in an ethical manner that involves affected communities -such usage of these tests could lead non-disclosed MSM to refrain from being tested or at least to question how healthcare personnel communicate, store, and, indeed, see their results. Building on earlier research, the Center for HIV Law and Policy states that mistrust could increase among vulnerable communities that already mistrust medical authorities. ${ }^{7}$ The process of translating phylogenetic testing from clinic to surveillance seems to pose some serious ethical but also epistemological questions with respect to our capacity to tell the truth about our sexuality, our health, and our risks-a matter that can further be connected to the notion of fidelity in translation. I began this article with a section on translation and how it transforms and sometimes betrays the source message. Transposing this logic onto the process of translating clinical phylogenetic testing and repurposing it as an HIV surveillance tool, one might ask what forms of betrayal this process might engender. If phylogenetic testing was originally intended to help care for people living with HIV by providing custom ARV regimens that took drug resistance into account, then how does fidelity to this usage remain in its new translated form? Circumventing the subject's capacity to talk about with whom they have sex and are connected through HIV transmissions seems to hold a troubling potential for betrayalespecially if data from such testing is stored, communicated, and used in manners that enable the "trahison" of "traduction."

\section{Molecular truths, surveillance, and subjectivities: speaking truthfully about sex and HIV}

From a Foucauldian perspective, phylogenetic molecular surveillance seems to profess an ability to provide panoptic surveillance at the molecular level and thus "show" us who is having 
sex with whom, who is not disclosing their risks, and who perhaps is even lying. Foucault's notion of panoptic surveillance comes from his work Discipline and Punish (Foucault, 2012). I want to briefly build on his work regarding disciplinary power and then link it to molecular surveillance.

Panopticism and disciplinary power heavily rely on visibility as a form of control. As Foucault states: "The panoptic mechanism arranges spatial unities that make it possible to see constantly and to recognize immediately. In short, it reverses the principle of the dungeon; or rather of its three functions-to enclose, to deprive of light and to hide-it preserves only the first and eliminates the other two. Full lighting and the eye of a supervisor capture better than darkness, which ultimately protected. Visibility is a trap" (Foucault, 2012, p. 200). Molecular HIV surveillance provides this sort of visibility, both offering a window into HIV transmission networks and producing a "map" depicting how risk networks and transmission clusters are spatially configured. Molecular HIV surveillance also opens a window into a subject's sexual practices, as we saw in the case of non-disclosed MSM. Such visibility also empowers molecular HIV surveillance to map spatial configurations and "see" across networks of people connected by their HIV viremia and preferred form of intimacy. Surveillance through the visibility accorded by molecular HIV surveillance generates knowledge about people's intimate lives and their networks. Moreover, molecular HIV surveillance, like disciplinary power, is built on "hierarchical observation, normalizing judgment and their combination in a procedure that is specific to it, the examination" (Foucault, 1995, p. 170). In the case of hierarchical observation Foucault notes that:

for although surveillance rests on individuals, its functioning is that of a network of relations from top to bottom, but also to a certain extent from bottom to top and laterally; this network holds the whole together and traverses it in its entirety with effects of power that derive from one another: supervisors, perpetually supervised. The power in the hierarchized surveillance of the disciplines is not possessed as a thing, or transferred as a property; it functions like a piece of machinery. (Foucault, 2012, p. 176)

Molecular HIV surveillance clearly adheres to this description; while the burden of getting HIV tested rests on individuals, the entire machinery of such surveillance functions as a way of observing, extracting data from, and ultimately intervening in a risk network and a transmission cluster. Molecular HIV surveillance concerns extracting data (phylogenetic information) to uncover relations across the network. In turn, this knowledge can be used for a variety of purposes, ranging from the benign (connecting people to care, providing prevention options such as PrEP) to the malignant (criminal prosecution and legal measures). This machinery pivots largely on the very examination so central to Foucault. "The examination combines the techniques of an observing hierarchy and those of a normalizing judgment. It is a normalizing gaze, a surveillance that makes it possible to qualify, to classify and to punish" (Foucault, 2012, p. 184). Molecular HIV surveillance can be seen as just such an examination, for by examining the phylogenetic data of a patient's blood, medical authorities can qualify and classify what risks have been taken, who has been intimate with whom, and to which "risk group" a patient belongs according to epidemiological knowledge regimes. Conversely, legal authorities can use the information derived from phylogenetic data to punish individuals by criminalizing HIV transmission.

Once again, using molecular HIV surveillance as a form of disciplinary and panoptic surveillance machine entails a power to make certain factors visible and then to order various subjects into different categories-MSM, risk networks, transmission clusters, etc.
This power to lay the molecular connections between people bare orders and categorizes people and spaces by coupling the knowledge derived from seeing what molecular HIV surveillance elucidates and the power of hierarchical observation and examination.

A word of caution on simplistically reading Foucault's disciplinary panoptic power and HIV surveillance: analyzing discipline is an undertaking to investigate how disciplinary power molds bodies and behaviors. However, such an analysis should not be taken to claim that people will actually comply with disciplinary regimes or that they will continually feel threatened by them. Rather, people also find ways to adapt to, avoid, live with, and resist such powers (Dumm, 2002). However, as I later show, communities are making several arguments against the disciplinary power of these HIV surveillance systems.

In this sense, as part of a panoptic machinery, the knowledge about genetic familiarity between HIV viremia observed through the phylogenetic test produces the power to "know" with whom people are having sex, while also constituting potential forensic medical surveillance admissible as circumstantial evidence in court (Abecasis et al., 2018; Bernard et al., 2007). As such, to speak of molecular HIV surveillance as a form of panopticism is not just a theoretical point, but also a function of the power to observe and then infer intimate truths about a subject that might even be used against them in a court of law.

Tim Dean has made this argument in the instance of viral load measurements, which he maintains also provide a panoptic surveillance system for monitoring whether patients are taking their HIV medications (Dean, 2015). When monitoring active drug levels in dry blood drawn from people living with HIV, clinicians can determine the level of adherence to the drug treatment by relying on the objective measure of active drug levels detected rather than on the patient's reported compliance. As seen above, similar molecular surveillance methods seem to be in play for uncovering with whom people are intimate. Both technologiesmolecular transmission tracing and blood tests for active drug levels to monitor adherence-offer ways of circumventing the subject's own willingness to disclose either adherence levels or with whom they have sex. This in and of itself, I argue, is an ethical issue that needs further exploration. It also inserts such surveillance technologies into the larger discussion on molecular biopolitics, as it figures in the scholarship of Nikolas Rose (Rabinow and Rose, 2003, 2006; Rose, 2007), which focuses on the tension between genetic risk and responsibility and the way a molecular optic "transforms the relations between patient and expert in unexpected ways, and is linked to the development of novel "life strategies", involving practices of choice, enterprise, self-actualization and prudence in relation to one's genetic makeup" (Novas and Rose, 2000, p. 1).

I argue, however, that molecular HIV surveillance is less about optimizing health or life itself and more about allegedly optimizing the gaze of public health surveillance. Molecular traces are currently mapped to produce new ways of spatializing HIV through the molecular bonds that bind people living with HIV, thus engendering new notions of connectivity, networks, and risk. This, I contend, is also the result of a translation process. If translation, as understood in STS and actor-network theory (ANT), postulates that translation produces new associations and new connections, then molecular HIV surveillance appears to offer a way of thinking through precisely how concepts like "risk networks" and "transmission networks" create new networks. However, as I have tried to argue in the above, one should also seek to evaluate what these concepts mask as much as what they unmask. In creating new associations and new networks, molecular HIV surveillance also seems to sever or conceal other aspects of HIV transmission, such as structural drivers, cultural aspects, and economic disparities. 
Pivoting back to Tim Dean, I agree that this sort of surveillance medicine belongs to the historical moment when "biopower extended its reach inside human bodies via drugs that regulate sexuality at the molecular level" (Dean, 2015, p. 236). Dean connects this moment to the introduction of the birth control pill, building on this argument to add the introduction of preexposure prophylaxis (PrEP) against HIV as a step in the movement to extend biopower to the molecular level. Preciado and Dean argue that "power acts through molecules that incorporate themselves into our immune system. Biopower gets inside us not only through psychological mechanisms of identification (as we figure out who we truly are sexually) but also through the pharmaceuticals we ingest to become the sexual beings we aspire to be" (Preciado cited in, Dean, 2015, p. 237). However, I would like to reverse this argument: rather than reading how pharmaceuticals alter our molecules so we can become sexual citizens or engage with sexual practices, molecular HIV surveillance exerts biopower in its ability to infer our risks, our sexual and intimate lives through the molecular bonds that bind us through HIV viremia.

Biopower in this optic is not something that gets inside us or is pharmaceutically incorporated into our immune system, but rather extracted and inferred from us through molecular genotyping of HIV viremia. Surveillance and truth-telling have thus become miniaturized and molecularized in a way that extends surveillance medicine. As Preciado notes: "We are gradually witnessing the miniaturization, internalization, and reflexive introversion (an inward coiling toward what is considered intimate, private space) of the surveillance and control mechanisms of the disciplinary sexopolitical regime" (Preciado, 2013, p. 79). This turn towards the subject's interiority by way of molecular HIV surveillance affects the subjectivity of people living with or at risk of HIV. What is more, such a turn has potentially grave ethical ramifications concerning stigma, consent, and the criminalization of HIV, but also, as argued above, concerning the understanding we might come to have regarding what can be said about sex and sexuality in relation to the tension between the subject's own sense of risk, desire, and sex and that of molecular HIV surveillance. These ethical issues deal with how we can truthfully speak about sex, how we frame risk and responsibility. Molecular HIV surveillance opens up a clearly problematic space in terms of how it proposes to "speak truthfully" about a person's risk and HIV transmission history, as well as of how whole communities are to reform HIV landscapes.

When phylogenetic testing is translated from the clinic to the domain of epidemiological surveillance, one extracts knowledge completely different from the information attained from molecules in the blood of people living with HIV. Indeed, the focus shifts from the extraction of information on the drug resistance levels of a particular HIV strain to become a trace of whom people are intimate with, whom they desire, and what kinds of risks they take. In other words, this translation process produces information that is somehow indexical. By this I mean that information on genetic kinship between similar HIV strains becomes an index for whom people are intimate with, for what they desire, and to a certain degree also an indexical sign indicating their type of sexual identity (e.g. non-disclosed MSM or men who identify as heterosexual but have sex with transgender women).

The repurposing of phylogenetic testing from clinical usage to molecular surveillance shows us how molecular technologies repurposed for surveillance suddenly also serve to amplify stigmatization through a manner of "molecular panopticon of suspicion." Here, the technological apparatus of molecular testing threatens to override the subject's capacity to tell "the truth" about desire, risk, and transmission. The crossover from clinic to surveillance seems to indicate the common capacity or aspiration of these HIV technologies to reveal "hidden truths" at the molecular level, discern risks unknown to the subjects themselves, and unmask both people's sexual networks and their connectivity as established through a molecular bond.

Notably, molecular HIV surveillance as a form of health governmentality entails a paradox. From a Foucauldian perspective, one has a hard time distinguishing whether the discourse on phylogenetic surveillance is either oppressive or liberating. As I have sought to show, almost all the articles analyzed emphasize the liberating and empowering potential of phylogenetic HIV surveillance-a potential highlighted through a focus on the ability of molecular HIV surveillance to map and uncover people with higher risk of HIV who need preventive services or, if testing positive, to be linked to care. Through a Foucauldian lens, this is precisely the point, for it is especially in the promises of liberation that power is at play (Foucault, 1980, 1990). Accordingly, molecular surveillance as a tool for discipline and surveillance is perhaps the flip side of the coin holding the more pastoral, health-promoting function promised by HIV science. In other words, while HIV science postulates that this technology can do good and be part of effective prevention strategies, HIV activists and legal experts are concerned that, used wrongly, it will do more harm than good.

\section{Repurposing as translation: a few comments on translation and surveillance}

I began this article by claiming that the repurposing of phylogenetic HIV testing from clinical usage to surveillance could be seen as a form of translation. I further argued that translation thus involves a crossover of uses that goes beyond the clinic, as phylogenetic testing has extended the knowledge it can extract to new health domains. By implicitly drawing on STS streams of thought, I have argued that the repurposing of phylogenetic testing can be read as a translation process involving the creation of new associations and connections not existing in the original usage of the technology. For example, one can make many associations by using the genetic bond that people share through HIV to link them into transmission and risk networks. Another set of new connections arising within this new usage concerns the connections between genetic information and surveillance and between routine clinical care and the broader HIV surveillance network in place. In making this claim, I should also say a few words on its theoretical implications vis-à-vis translation as a perspective, as well as on the Foucauldian framework that I have relied on.

Space considerations prevent a close analysis of how translation and biopolitical HIV surveillance diverge and converge, but I would nevertheless like to raise a related point. Both Foucaultinspired work and the ANT tradition, which-at least implicitlyhave inspired me, view actants and concepts to be relational insofar as both traditions assume that contextualized networks and discursive formations determine how such actants and concepts work. Seen either as an actant or as a concept, phylogenetic testing is inherently always contingent on the broader context in which it is embedded. As far as this constitutes a convergence, I want to argue that how phylogenetic testing and subsequent networks or discursive formations function is always open for change because their usage is contextual. This is where translation as a concept becomes useful, as it can help one understand how change comes about when technology moves or crosses over from one knowledge domain to another-in this case from clinical care to molecular HIV surveillance. From an ANT perspective, the phylogenetic HIV test is an actant that allows a multiplicity of networks to form. In the Foucauldian sense, the phylogenetic test 
is perhaps best understood as always being in a force field of power (Foucault, 1990), and its potential for either liberation or oppression as being ever contextual and contingent. One can therefore not determine a priori whether the test will, within a given reference frame, be liberating, oppressive, or both.

This elucidates a point where the two perspectives diverge. For Foucault, the historical genealogy of the technology concerned is important, but so is the broader genealogy of health surveillance and governmental practices, as exemplified in his work on various confessional (Foucault, 1990) and disciplinary technologies (Foucault, 2012). Conversely, the ANT tradition focuses less on the genealogical and more on the contemporary and contextual. Transposed to phylogenetic HIV testing, ANT could be viewed as less concerned with the genealogy of health surveillance and public health governmentality, seeking instead to investigate the networks of which phylogenetic testing becomes part, how the test acts and who it acts upon. Michel Callon follows this line of thinking in his seminal work on scallops (Callon, 1984), a similar study of which could have been done on phylogenetic HIV testing.

\section{The ethics of it all: consequences of translation}

As argued above, translating the use of molecular HIV surveillance pivots on the ethical issues of consent and stigma. Whereas a patient must always explicitly consent to an HIV test, this consent is not required for the subsequent genotypic test and data material. Phylogenetic data is sent directly to databanks without patients' consent or, perhaps, even knowledge. This is a worrisome practice because many states and nations still criminalize HIV and onwards HIV transmission to some extent or other (McClelland et al., 2019). While directionality cannot be inferred through phylogenetic testing, the use of such technology has been admitted as forensic evidence in several countries' courts (Bernard et al., 2007). However, Bernard et al. warn that using surveillance data as forensic evidence of "reckless HIV transmission" needs to be backed up with a solid, evidence-based case and that "over-interpreting the results of phylogenetic analyses is unacceptable, regardless of how convinced an expert may be of the guilt or innocence of the accused" (Bernard et al., 2007, p. 386). As such, the danger of forensically misusing phylogenetic testing as a form of forensic technology is an issue that in and of itself raises serious ethical questions.

From a public health perspective, the ethics of resources come into play, and there is evidence that such surveillance serves its intended purpose. As McClelland et al. state: "as of 1 January 2018, the CDC has started providing funding to all health departments for the reporting and monitoring of these results as part of efforts to expand the scale-up of molecular surveillance" (McClelland et al., 2019). Yet, the body of evidence that molecular HIV surveillance is cost-effective, reduces the incidence of HIV, and links more people to care and treatment remains inconclusive. The Center for HIV Law and Policy notes: "It is also not clear that this data, which comes from people already in care, provides uniquely useful prevention information that is otherwise unavailable." ${ }^{8}$ In an interview Naina Khanna, executive director of Positive Women's Network, expressed skepticism that such technology "provides anything we don't already know or couldn't get from sitting down with a group of transgender women in LA. She worries that these analyses are becoming more common because researchers get excited about fancy new technologies and consistently undervalue old-fashioned social science research, and not because the new technologies add anything of importance." 9 Her statement also highlights the need to critically engage with what is or is not funded and how this new form of HIV surveillance might siphon funding from other more traditional public health initiatives, thus depleting funding for a technology whose declared ability has yet to be validated.

The Center for HIV Law and Policy notes that the abovementioned ethical and legal issues intersect at a historical moment when several other legal and policy issues are eroding the rights of people living with HIV, as well as potentially heightening stigma and increasing distrust in medical institutions among vulnerable communities. These issues include "numerous efforts to bypass basic patient protections in the name of ending the HIV epidemic, including a legislative proposal to dispense with direct notice and consent of HIV test in New York ${ }^{10}$ and a new Louisiana policy to expand tracking of testing results." 11 The Center for HIV Law and Policy further states that many of these issues overlap at a juncture where at least two troubling trends intersect. First, a belief has arisen that, because the end of the HIV epidemic appears to be in sight, any means to that end is justified, even at the cost of medical ethics and respect for the dignity of people living with HIV and of marginalized communities. Second, the misperception has taken hold that a greater representation of people living with HIV means that policymakers need not consider persistent HIV stigma and legal jeopardy-a misperception evinced in the large number of states that still penalize HIV nondisclosure. ${ }^{12}$

This matrix of socio-political issues also informs the usage of molecular HIV surveillance and fuels the belief in its efficacy. I have argued that, unless carefully navigated, the turn towards a form of "molecular truth-telling" could risk overriding the individual's sense of sexual identity, desires, and notions of how to reconcile risk and pleasure. Although molecular HIV surveillance is indeed a potent form of surveillance, we should question its usage and its many unintended ethical pitfalls, as well as insist on a clear ethical and legal framework built on an engagement with stakeholders and research communities that does not end up in a panoptic molecular form of surveillance-a variation on truthtelling that ultimately stigmatizes communities.

\section{Data availability}

This article is not based on any qualitative date such as interviews, or field notes, nor is it based on data sets such consisting of numbers, statistics or the like. The article was conducted based on a content analysis of the following academic articles, as well as those cited and listed in the references list (Haillon et al., 2017; Chan et al., 2015; Dennis et al., 2015; German et al., 2017; González-Alba et al., 2011; Hué et al., 2014; Little et al., 2014; Oster et al., 2015, 2018a, 2018b; Poon et al., 2016; RagonnetCronin et al., 2019; Smith et al., 2009; Wirden et al., 2019).

Received: 28 November 2019; Accepted: 16 June 2020; Published online: 08 July 2020

\section{Notes}

1 See the CDC's information sheet about this: https://www.cdc.gov/hiv/ programresources/guidance/molecular-cluster-identification/qa.html.

2 See the CDC's Q\&A on molecular surveillance: https://www.cdc.gov/hiv/ programresources/guidance/molecular-cluster-identification/qa.html.

3 See the CDC Q\&A on molecular HIV surveillance: https://www.cdc.gov/hiv/ programresources/guidance/molecular-cluster-identification/qa.html.

4 See, for instance, the Independent. https://www.independent.co.uk/news/world/ americas/us-politics/donald-trump-suggested-haitian-immigrants-have-aidsofficials-claim-a8126861.html

5 For a few recent examples of this in the media see The Guardian's article on this topic in England: https://www.theguardian.com/politics/2014/oct/10/nigel-farage-defendsplan-immigrants-hiv-nhs; the Newsweek article on the topic as it circulated in the USA: https://www.newsweek.com/donald-trump-says-migrants-bring-large-scalecrime-and-disease-america-1253268; Huffington Post's article on Main Governor 
Paul LePage's statement about the topic: https://www.huffpost.com/entry/paullepage-immigration-disease_n_6616000?

guccounter $=1$ \&guce_referrer=aHR0cHM6Ly93d3cuZ29vZ2xlLmNvbS8\&guce_referrer_sig=AQAAALjf8HZcy54yQo5tknth1EROHyBAkQ-

JuVDJjMpvt44G65zHrxd2QUXvfQdRkuFRvvfEVVDEpPES5rouzjryy1C8Az4x4Ax_0pzCebzplvifwrjZVk2FYmAIU_e1-2vM_1i4Zo46UkcxDRLAQAKSAeQUByE6aGeaGJuofPCJgyS; and the Guardian's article on Italian authorities handling of boat refugees and the notion that they "bring HIV" to Italy: https://www. theguardian.com/world/2018/nov/20/italy-orders-seizure-aquarius-migrant-rescueship-hiv-clothes.

6 See Naina Khanna’s statement: https://www.thebodypro.com/article/concerns-overuse-of-molecular-hiv-surveillance.

7 See the Center for HIV Law and Policy: http://www.hivlawandpolicy.org/sites/ default/files/CHLP\%20Molecular\%20Surveillance\%20Final.pdf.

8 See the Center for HIV Law and Policy's' document "Is HIV Molecular Surveillance Worth The Risk?": http://www.hivlawandpolicy.org/sites/default/files/CHLP\% 20Molecular\%20Surveillance\%20Final.pdf.

9 See the article at the Bodypro.com: https://www.thebodypro.com/article/concernsover-use-of-molecular-hiv-surveillance.

10 See the New York Post article on the topic: https://nypost.com/2019/05/17/thewrong-way-to-improve-hiv-testing/.

11 See KTBS' news story: https://www.ktbs.com/news/3investigates/policy-changecould-lead-to-medical-privacy-problems/article_c17c5ad2-7836-11e9-9fda937b16210aae.html.

12 See the full article at: http://www.hivlawandpolicy.org/fine-print-blog/hiv-molecularsurveillance-worth-risk.

\section{References}

Abecasis AB, Pingarilho M, Vandamme A-M (2018) Phylogenetic analysis as a forensic tool in HIV transmission investigations. Aids 32(5):543-554

Bacchi C (2012) Why study problematizations? Making politics visible. Open J Polit Sci 2(01):1

Bacchi C (2015) The turn to problematization: political implications of contrasting interpretive and poststructural adaptations. Open J Polit Sci 2015 (5):1-12

Bacchi C, Goodwin S (2016) Poststructural policy analysis: a guide to practice. Springer Bernard EJ, Azad Y, Vandamme A-M, Weait M, Geretti AM (2007) HIV forensics: pitfalls and acceptable standards in the use of phylogenetic analysis as evidence in criminal investigations of HIV transmission HIV Med 8:382-387

Boulton M, Hart G, Fitzpatrick R (1992) The sexual behavior of bisexual men in relation to HIV transmission AIDS care 4:165-175

Brown SD (2002) Michel serres: science, translation and the logic of the parasite. Theory, Culture \& Society 19(3):1-27

Callon M (1984) Some elements of a sociology of translation: domestication of the scallops and the fishermen of St Brieuc Bay. Sociol Rev 32 (1_suppl):196-233

Castor D, Low A, Evering T, Karmon S, Davis B, Figueroa A, Markowitz M (2012) Transmitted drug resistance and phylogenetic relationships among acute and early HIV-1-infected individuals in New York City. J Acquir Immune Defic Syndr (1999) 61(1):1-8. https://doi.org/10.1097/QAI.0b013e31825a289b

Chaillon A, Essat A, Frange P, Smith DM, Delaugerre C, Barin F (2017) Spatiotemporal dynamics of HIV-1 transmission in France (1999-2014) and impact of targeted prevention strategies. Retrovirology 14(1):15-15. https://doi.org/ 10.1186/s12977-017-0339-4

Chan PA, Hogan JW, Huang A, DeLong A, Salemi M, Mayer KH, Kantor R (2015) Phylogenetic investigation of a statewide HIV-1 epidemic reveals ongoing and active transmission networks among men who have sex with men. J Acquir Immune Defic Syndr (1999) 70(4):428

Chow EP, Wilson DP, Zhang L (2011) What is the potential for bisexual men in China to act as a bridge of HIV transmission to the female population? Behavioral evidence from a systematic review and meta-analysis. BMC Infect Dis 11(1):242

Center for Disease Control (2018) Detecting and responding to transmission clusters: a guide for health departments, draft version 2.0. National Center For HIV/AIDS, Viral Hepatitis, STD, and TB Prevention

Dean T (2015) Mediated intimacies: raw sex, truvada, and the biopolitics of chemoprophylaxis. Sexualities 18(1-2):224-246

Dennis AM, Hué S, Pasquale D, Napravnik S, Sebastian J, Miller WC, Eron JJ (2015) HIV transmission patterns among immigrant Latinos illuminated by the integration of phylogenetic and migration data. AIDS Res Hum Retrov 31 (10):973-980

Dumm TL (2002) Michel Foucault and the politics of freedom. Rowman \& Littlefield

Elo S, Kyngäs H (2008) The qualitative content analysis process. J Adv Nursing 62 (1):107-115

Epstein S (1996) Impure science: AIDS, activism, and the politics of knowledge (Vol. 7). Univ of California Press
Farmer P (2006) AIDS and accusation: Haiti and the Geography of Blame. Univ of California Press

Foucault M (1980) Power/knowledge: selected interviews and other writings, 1972-1977. Pantheon

Foucault M (1990) The history of sexuality: an introduction, vol I (Hurley R (Trans.)). Vintage (Original work published in 1982)

Foucault, M (1995) Discipline and punish: the birth of the prison. New York. Vintage Books

Foucault M (2002) The birth of the clinic. Routledge

Foucault M (2008) The birth of biopolitics: lectures at the Collège de France, 1978-1979. Springer

Foucault M (2012) Discipline \& punish. The birth of the prison. Vintage

Foucault M, Davidson, AI, Burchell G (2010). The government of self and others: lectures at the Collège de France 1982-1983. Springer

Gardy JL (2016) Translating phylogeny into action for HIV surveillance. Lancet HIV 3(5):e196-e197

German D, Grabowski MK, Beyrer C (2017) Enhanced use of phylogenetic data to inform public health approaches to HIV among men who have sex with men Sex Health 14(1):89-96. https://doi.org/10.1071/SH16056

González-Alba JM, Holguín A, Garcia R, García-Bujalance S, Alonso R, Suárez A, García-Bermejo I (2011) Molecular surveillance of HIV-1 in Madrid, Spain: a phylogeographic analysis. J Virol 85(20):10755-10763

Han C-S (2015) No brokeback for black men: pathologizing black male (homo) sexuality through down low discourse. Soc Identities 21(3):228-243

Haillon A, Essat A, Frange P, Smith DM, Delaugerre C, Barin F, Ghosn J, Pialoux G, Robineau O, Rouzioux C, Goujard C, Meyer L, Chaix M-L, On Behalf of the, APCS (2017) Spatiotemporal dynamics of HIV-1 transmission in France (19992014) and impact of targeted prevention strategies. Retrovirology 14:15-15

Hué S, Brown AE, Ragonnet-Cronin M, Lycett SJ, Dunn DT, Fearnhill E, Delpech VC (2014) Phylogenetic analyses reveal HIV-1 infections between men misclassified as heterosexual transmissions. Aids 28(13):1967-1975

Huet T, Cheynier R, Meyerhans A, Roelants G, Wain-Hobson S (1990) Genetic organization of a chimpanzee lentivirus related to HIV-1. Nature 345(6273):356

Ingram A (2008) Domopolitics and disease: HIV/AIDS, immigration, and asylum in the UK. Environ Plan D 26(5):875-894

Lai A, Bergna A, Simonetti FR, Franzetti M, Bozzi G, Micheli V,... Ciccozzi M (2020) Contribution of transgender sex workers to the complexity of the HIV-1 epidemic in the metropolitan area of Milan. Sex Transm Infect 0:1-16 [Epub ahead]

Law J (2006) Traduction/trahison: notes on ANT. Convergencia 13(42):47-72

Little SJ, Pond SLK, Anderson CM, Young JA, Wertheim JO, Mehta SR, Smith DM (2014) Using HIV networks to inform real-time prevention interventions. PLoS ONE 9(6):e98443

Mayring P (2004) Qualitative content analysis. In: A companion to qualitative research, vol 1. Sage, pp. 159-176

McClelland A, Guta A, Gagnon M (2019) The rise of molecular HIV surveillance: implications on consent and criminalization. Crit Public Health, 1-7. https:// doi.org/10.1080/09581596.2019.1582755

Montgomery JP, Mokotoff ED, Gentry AC, Blair JM (2003) The extent of bisexual behaviour in HIV-infected men and implications for transmission to their female sex partners. AIDS Care 15(6):829-837

Novas C, Rose N (2000) Genetic risk and the birth of the somatic individual. Econ Soc 29(4):485-513

Oster AM, France AM, Mermin J (2018a) Molecular epidemiology and the transformation of HIV prevention. JAMA 319(16):1657-1658

Oster AM, France AM, Panneer N, Ocfemia MCB, Campbell E, Dasgupta S, Hernandez AL (2018b) Identifying clusters of recent and rapid HIV transmission through analysis of molecular surveillance data. J Acquir Immune Defic Syndr 79(5):543-550

Oster AM, Wertheim JO, Hernandez AL, Ocfemia MCB, Saduvala N, Hall HI (2015) Using molecular HIV surveillance data to understand transmission between subpopulations in the United States. J Acquir Immune Defic Syndr 70(4):444

Persson A, Newman C (2008) Making monsters: heterosexuality, crime, and race in recent Western media coverage of HIV. Sociol Health Illn 30(4):632-646

Poon AF, Gustafson R, Daly P, Zerr L, Demlow SE, Wong J, Moore D (2016) Near real-time monitoring of HIV transmission hotspots from routine HIV genotyping: an implementation case study. Lancet HIV 3(5):e231-e238

Preciado, PB (2013) Testo junkie: sex, drugs, and biopolitics in the pharmacopornographic era. The Feminist Press, CUNY

Rabinow P, Rose N (2003) Thoughts on the concept of biopower today. The Molecular Sciences Institute, vol 1

Rabinow P, Rose N (2006) Biopower today. BioSocieties 1(2):195-217

Ragonnet-Cronin M, Hodcroft EB, Wertheim JO (2019a) Understanding disclosed and cryptic HIV transmission risk via genetic analysis: what are we missing and when does it matter? Curr Opin HIV AIDS 14(3):205-212

Ragonnet-Cronin M, Hu YW, Morris SR, Sheng Z, Poortinga K, Wertheim JO (2019b) HIV transmission networks among transgender women in Los Angeles County, CA, USA: a phylogenetic analysis of surveillance data. Lancet HIV 6(3):e164-e172 
Ragonnet-Cronin M, Hué S, Hodcroft EB, Tostevin A, Dunn D, Fawcett T, Brown AJL (2018) Non-disclosed men who have sex with men in UK HIV transmission networks: phylogenetic analysis of surveillance data. Lancet HIV 5 (6):e309-e316. https://doi.org/10.1016/S2352-3018(18)30062-6

Rose N (2007) Molecular biopolitics, somatic ethics, and the spirit of biocapital. Soc Theor Health 5(1):3-29

Sangaramoorthy T (2014) Treating AIDS: politics of difference, paradox of prevention. Rutgers University Press

Smith DM, May S, Tweeten S, Drumright L, Pacold ME, Pond SLK, Woelk CH (2009) A public health model for the molecular surveillance of HIV transmission in San Diego, California. AIDS (London, England) 23(2):225

Stone BE (2011) The down low and the sexuality of race. Foucault Stud

Taylor B, Sapién H (2020) Determining the direction of HIV transmission: benefits and potential harms of taking phylogenetic analysis one step further. Clin Infect Dis. https://doi.org/10.1093/cid/ciz1248

Treichler PA (1999) How to have theory in an epidemic: cultural chronicles of AIDS. Duke University Press

Wintroub M (2015a) The translations of a humanist ship captain: Jean Parmentier's 1529 voyage to sumatra. Renaiss Q 68(1):98-132

Wintroub M (2015b) Translations: words, things, going native, and staying true. Am Historic Rev 120(4):1185-1217

Wirden M, De Oliveira F, Bouvier-Alias M, Lambert-Niclot S, Chaix M-L, Raymond S,... Bellecave P (2019) New HIV-1 circulating recombinant form 94: from phylogenetic detection of a large transmission cluster to prevention in the age of geosocial-networking apps in France, 2013 to 2017. Eurosurveillance 24(39):1-10

Wood RW, Krueger LE, Pearlman TC, Goldbaum G (1993) HIV transmission: women's risk from bisexual men. Am J Public Health 83(12):1757-1759

\section{Competing interests}

The author declares no competing interests.

\section{Additional information}

Correspondence and requests for materials should be addressed to T.S.

Reprints and permission information is available at http://www.nature.com/reprints

Publisher's note Springer Nature remains neutral with regard to jurisdictional claims in published maps and institutional affiliations.

(c) (i) Open Access This article is licensed under a Creative Commons Attribution 4.0 International License, which permits use, sharing adaptation, distribution and reproduction in any medium or format, as long as you give appropriate credit to the original author(s) and the source, provide a link to the Creative Commons license, and indicate if changes were made. The images or other third party material in this article are included in the article's Creative Commons license, unless indicated otherwise in a credit line to the material. If material is not included in the article's Creative Commons license and your intended use is not permitted by statutory regulation or exceeds the permitted use, you will need to obtain permission directly from the copyright holder. To view a copy of this license, visit http://creativecommons.org/ licenses/by/4.0/.

(C) The Author(s) 2020 